\title{
Impaired fasting glucose levels in overweight or obese subjects for screening of type 2 diabetes in Korea
}

Jin-Hee Lee ${ }^{1, *}$, Suk Chon ${ }^{2,}$, Seon-Ah Cha ${ }^{3}$, Sun-Young Lim ${ }^{1}$, Kook-Rye Kim³ ${ }^{3}$ Jae-Seung Yun ${ }^{3}$, Sang Youl Rhee ${ }^{2}$, Kun-Ho Yoon ${ }^{1,4}$, Yu-Bae Ahn ${ }^{3}$, Jeong-Taek Woo ${ }^{2}$, Seung-Hyun $\mathrm{Ko}^{3}$, and Korean Diabetes Prevention Study Investigators

${ }^{1}$ Catholic Institute of Smart Healthcare Center, Institute of Biomedical Industry, The Catholic University of Korea, Seoul; ${ }^{2}$ Department of Endocrinology and Metabolism, Kyung Hee University School of Medicine, Seoul; ${ }^{3}$ Division of Endocrinology and Metabolism, Department of Internal Medicine, College of Medicine, St. Vincent's Hospital, The Catholic University of Korea, Suwon; ${ }^{4}$ Division of Endocrinology and Metabolism, Department of Internal Medicine, College of Medicine, The Catholic University of Korea, Seoul, Korea

\section{Received: May 21, 2019 \\ Revised : July 1, 2019 \\ Accepted: July 5, 2019}

\section{Correspondence to}

Seung-Hyun Ko, M.D.

Division of Endocrinology and Metabolism, Department of Internal Medicine, St. Vincent's Hospital, College of Medicine, The Catholic University of Korea, 93 Jungbu-daero, Paldal-gu, Suwon 16247 , Korea

Tel: +82-31-881-8900

Fax: +82-31-253-8898

E-mail: kosh@catholic.ac.kr https://orcid.org/0000-00033703-1479

*These authors contributed equally to this work.

Background/Aims: We examined the concordance rate among fasting plasma glucose (FPG), 2-hour post-challenge glucose (2hr PG), and hemoglobin Aic (HbArc) in the diagnosis of diabetes in a population with a high-risk for type 2 diabetes mellitus (T2DM) in Korea.

Methods: Among the participants from the Korean Diabetes Prevention Study, individuals with FPG $\geq 100 \mathrm{mg} / \mathrm{dL}$, body mass index $(\mathrm{BMI}) \geq 23.0 \mathrm{~kg} / \mathrm{m}^{2}$, and no previous history of $\mathrm{T} 2 \mathrm{DM}$ were consecutively enrolled after a $75 \mathrm{~g}$ glucose tolerance test. We analyzed the differences in the clinical characteristics in subjects with stage 1 (FPG, 100 to $109 \mathrm{mg} / \mathrm{dL}$ ) and stage 2 (FPG, 110 to $125 \mathrm{mg} / \mathrm{dL}$ ) impaired fasting glucose (IFG).

Results: Of 1,637 participants, $27.2 \%$ had T2DM and 59.3\% had IFG and/or impaired glucose tolerance (IGT). The mean age was $55.0 \pm 8.1$ years and the mean BMI was $26.3 \pm 2.7 \mathrm{~kg} / \mathrm{m}^{2}$. Based on FPG criteria, $515(31.4 \%)$ and $352(21.5 \%)$ subjects were classified as having stage 1 and stage 2 IFG, respectively. The $19.0 \%$ of stage 1 and $43.5 \%$ of stage 2 subjects showed $2 \mathrm{hr}$ PG levels in the diabetic range. Even for those in the normal FPG range, 63 (9.5\%) participants showed a $2 \mathrm{hr}$ PG level of $\geq 200 \mathrm{mg} / \mathrm{dL}$. Of 446 subjects with newly-diagnosed diabetes, 340 (76.2\%) showed FPG levels $<126 \mathrm{mg} / \mathrm{dL}$.

Conclusions: The oral glucose tolerance test should be actively considered for Korean adults who are overweight or obese with the IFG range (FPG, 100 to $125 \mathrm{mg}$ / $\mathrm{dL}$ ) to allow for early detection of diabetes and prompt intervention.

Keywords: Diabetes mellitus, type 2; Prediabetic state; Impaired fasting glucose; Overweight; Hemoglobin Aic

\section{INTRODUCTION}

In 2016 , the prevalence of diabetes in adults aged 30 years and older in Korea was $14.4 \%$, and the number of patients with diabetes was estimated to be about
5 million people [1]. Moreover, the high prevalence of prediabetes (increased risk for diabetes), as compared to that of diabetes, is a serious health concern that requires urgent intervention. The overall prevalence of impaired fasting 
glucose (IFG) in Korea was estimated at 8.7 million, or approximately $25.3 \%$ of the Korean population in 2016 [1]. Early detection of prediabetes is extremely important because early intervention with lifestyle modification can prevent the progression of prediabetes to type 2 diabetes mellitus (T2DM) [2]. Without prompt intervention, nearly two-thirds of individuals with prediabetes who have both IFG and impaired glucose tolerance (IGT) are likely to progress to diabetes within several years [3]. With limited resources and budgets, targeted screening and early identification of subjects with a high risk of T2DM will maximize the efficiency of health care policy and ultimately lead to a reduced health burden [4].

Fasting plasma glucose (FPG) level has long been the gold standard used to diagnose diabetes [5]. However, many epidemiologic studies have shown that FPG alone cannot detect early diabetes in all patients who have 2-hour post-challenge glucose (2hr PG) concentrations from a $75 \mathrm{~g}$ oral glucose tolerance test (OGTT) within the diabetic range [3,6-10]. In addition, if FPG rather than $2 \mathrm{hr}$ PG is used for the diagnosis of diabetes, many subjects with IGT who are at risk of future cardiovascular disease (CVD) would not be identified. Practically, an OGTT is not routinely performed. Therefore, the addition of hemoglobin Alc (HbA1c) or other clinical marker with FPG is helpful to increase the detection rate of undiagnosed diabetes in routine clinical settings.

In the clinical practice guidelines (CPG) of the Korean Diabetes Association (KDA), screening for T2DM in non-pregnant adults (individuals 40 years and older or high-risk individuals aged 30 years and older) should be performed annually using FPG, a 75 g OGTT, or HbA1c [11]. Specifically, the KDA classifies prediabetes into two stages in the general population: stage 1 (FPG 100 to 109 $\mathrm{mg} / \mathrm{dL}$ or HbAic $5.7 \%$ to $6.0 \%$ ) and stage 2 (FPG 110 to $125 \mathrm{mg} / \mathrm{dL}$ or HbA1c $6.1 \%$ to $6.4 \%$ ). Based on these IFG criteria, the KDA recommends different action strategies in the clinical practice guidelines. For subjects with stage 1 IFG, the KDA recommends only FPG and HbAic measurements every year. In addition, the $75 \mathrm{~g}$ OGTT is recommended in individuals with stage 2 IFG to detect undiagnosed diabetes immediately [11]. However, it is not clear if this recommendation is applicable for the overweight or obese population based on the same criteria.

Currently, the Korean Diabetes Prevention Study (KDPS), which is the first randomized controlled clini- cal trial to prevent T2DM in high-risk adult individuals with diabetes through intensive lifestyle management or metformin administration has been going on since July $2016[12,13]$. Subjects who are overweight or obese (body mass index $[\mathrm{BMI}] \geq 23.0 \mathrm{~kg} / \mathrm{m}^{2}$ ) with FPG $\geq 100 \mathrm{mg} / \mathrm{dL}$ were screened, after which a $75 \mathrm{~g}$ OGT'T with HbA1c level measurement was performed. From this screening data, we analyzed and compared the three diagnostic results to detect diabetes according to the FPG stage.

The aim of this study was to investigate whether stage 1 and 2 criteria were applicable in the overweight or obese individuals of the IFG population in Korea.

\section{METHODS}

The study design of the KDPS has been described elsewhere $[12,13]$. In brief, the KDPS was divided into two intervention studies: a hospital-based (H-KDPS) and a community-based intervention study (C-KDPS). The $\mathrm{H}-\mathrm{KDPS}$ is a prospective, multi-center, randomized, open-label controlled trial for preventing T2DM performed throughout 10 university-affiliated hospitals in Korea. The C-KDPS is a prospective, community-based randomized intervention trial for preventing $\mathrm{T} 2 \mathrm{DM}$ that uses a web-based program conducted in two public health centers in Korea (Chungju and Suwon City). The baseline examination was performed between 1 July, 2016 and 31 October, 2018 for a 75 g OGTT with HbA1c determination and a cardiovascular risk factor assessment $[12,13]$. We analyzed the screening data of subjects aged 30 to 70 years with a BMI of $\geq 23.0 \mathrm{~kg} / \mathrm{m}^{2}$ who also had IFG but no history of T2DM.

Exclusion criteria were as follows: previous diagnosis of diabetes or diabetes treatment; uncontrolled hypertension or significant ischemic heart disease requiring hospitalization within 6 months of enrollment; either heart failure, anemia, cancer requiring treatment in the past 5 years, or renal insufficiency; severe liver dysfunction or alcohol abuse; significant arthritis or psychiatric problems; either pregnant or planning to become pregnant; several medications (thiazide, beta blockers, steroid, immune-modulating agents, agents for weight reduction); and other systemic illnesses affecting the performance of this intervention program. 


\section{Data collection}

After providing informed consent, subjects underwent a $75 \mathrm{~g}$ OGT'T with HbAic level measurement. Then, completed questionnaires regarding the medical history of chronic disease (i.e., hypertension, diabetes mellitus and dyslipidemia), smoking or alcohol use, and lifestyle habits as well as anthropometric measurements were obtained from the participants.

We calculated the BMI from body weight and height, which were measured by standard methods. Waist circumference was measured in the standing position at a level midway between the lowest rib and the iliac crest after normal respiration. Measurement was performed by well-trained examiners using a standard nonstretchable tape. Blood pressure (BP) was measured with the participant in the seated position for 30 minutes. We calculated the mean value of BP from three measurements with less than $5 \mathrm{mmHg}$ differences. Smoking status was classified into three main categories: current smokers, ex-smokers, and never smoked. Additionally, the amount of cigarette smoking was evaluated by pack per day multiplied by years (pack-year). Alcohol intake was evaluated by the frequency and quantity of Korean distilled spirits, beer, wine, and sake intake during the previous 12 months, and quantification of alcohol use was estimated in terms of average drinking (grams of pure alcohol per day).

We analyzed data from the baseline OGTT and HbAic measurements. All laboratory parameters, including lipid profiles, were measured after overnight fasting and evaluated in the central laboratory (Seegene Medical Foundation, Seoul, Korea). FPG and $2 \mathrm{hr}$ PG were determined with a Cobas C702 analyzer (Cobas 8000 C702, Roche, Mannheim, Germany) with a NaF-contained bottle. HbAic was measured on the same day with a high-performance liquid chromatography method (Tosoh HLC-723 G8, Sysmex, Tokyo, Japan). Serum total cholesterol, triglycerides (TG), high-density lipoprotein cholesterol and low-density lipoprotein cholesterol were determined by using a chemistry analyzer (Cobas 8000 C702).

The hospital-based KDPS (H-KDPS) has been registered with the Clinical Research Information Service, Republic of Korea (KCTooo2260). In addition, the community-based KDPS (C-KDPS) has been registered with the Clinical Research Information Service, Republic of
Korea (KCToo01981). Both KDPS program protocols have also been reviewed and certified by the KDA and the Catholic University of Korea. This study was approved by the Institutional Review Board of St. Vincent's Hospital (No. VC16MISIooo3).

\section{Definition}

We defined diabetes and prediabetes according to the 2018 American Diabetes Association (ADA) recommendations. Diabetes was diagnosed based on plasma glucose criteria, either the FPG value of $\geq 126 \mathrm{mg} / \mathrm{dL}$ or the $2 \mathrm{hr}$ PG value of $\geq 200 \mathrm{mg} / \mathrm{dL}$ during a $75-\mathrm{g}$ OGTT, or $\mathrm{AlC}$ value of $\geq 6.5 \%$. We defined prediabetes as an FPG value of 100 to $125 \mathrm{mg} / \mathrm{dL}$ and/or a $2 \mathrm{hr}$ PG value of 140 to $199 \mathrm{mg} / \mathrm{dL}$. Furthermore, the HbA1c criteria for diagnosing diabetes and prediabetes were $\geq 6.5 \%$ and $5.7 \%$ to $6.4 \%$, respectively [14].

\section{Statistical analysis}

All data are expressed as mean \pm standard deviation or number (\%). Initial statistical analyses included descriptive statistics and an assessment of normality of distributions. Distribution of variables was assessed by evaluation of the Shapiro-Wilk's test. Fisher's exact test was used to determine significant differences in proportions among categorical variables. Univariate analysis of variance was used with the least significant difference post hoc tests in order to determine the clinical characteristic difference according to the level of FPG. Nonparametric statistical tests were performed for HbAic, TG, alcohol intake and pack-years. Cohen's Kappa ( $\kappa$ ) statistics were used to find the agreement level between different definitions. Statistical analyses were performed using SAS version 9.3 (SAS Institute, Cary, NC, USA). A $p<0.05$ was considered significant.

\section{RESULTS}

In total, 1,637 participants were included in this study. The average age was $55.0 \pm 8.1$ years, $45.9 \%$ were males, the mean BMI value was $26.3 \pm 2.7 \mathrm{~kg} / \mathrm{m}^{2}$, and $29.4 \% \mathrm{had}$ hypertension. The mean FPG, 2 hr PG, and HbAlc values were 104.1 $\pm 14.2 \mathrm{mg} / \mathrm{dL}, 163.0 \pm 55.3 \mathrm{mg} / \mathrm{dL}$, and $5.9 \pm$ $0.5 \%$, respectively (Table 1 ).

Based on ADA criteria for the diagnosis of diabetes 
Table 1. Clinical characteristics and biochemical parameters of the study subjects

\begin{tabular}{|c|c|c|c|c|}
\hline Characteristic & Total $(\mathrm{n}=1,637)$ & Male $(\mathrm{n}=752)$ & Female $(\mathrm{n}=885)$ & $p$ value \\
\hline Age, yr & $55.0 \pm 8.1$ & $54.0 \pm 8.3$ & $55.8 \pm 7.8$ & $<0.001$ \\
\hline Height, $\mathrm{cm}$ & $162.8 \pm 8.8$ & $170.2 \pm 5.8$ & $156.4 \pm 5.2$ & $<0.001$ \\
\hline Weight, kg & $70.0 \pm 10.5$ & $76.5 \pm 9 \cdot 3$ & $64.5 \pm 8.1$ & $<0.001$ \\
\hline $\mathrm{BMI}, \mathrm{kg} / \mathrm{m}^{2}$ & $26.3 \pm 2.7$ & $26.3 \pm 2.6$ & $26.3 \pm 2.9$ & 0.958 \\
\hline WC, cm & $90.6 \pm 8.0$ & $92.6 \pm 7.1$ & $88.8 \pm 8.4$ & $<0.001$ \\
\hline Hypertension & $481(29.4)$ & $242(32.2)$ & $239(27.0)$ & 0.022 \\
\hline Dyslipidemia & $577(35 \cdot 3)$ & $223(29.7)$ & $354(40.0)$ & $<0.001$ \\
\hline Family history of DM & $723(44 \cdot 5)$ & $303(40.6)$ & $420(47.8)$ & 0.003 \\
\hline Current smoker & $198(12.1)$ & $184(24 \cdot 5)$ & $14(1.6)$ & $<0.001$ \\
\hline Current alcohol drinker & $930(56.8)$ & $607(80.7)$ & $323(36.5)$ & $<0.001$ \\
\hline $\mathrm{SBP}, \mathrm{mmHg}$ & $124.9 \pm 13.0$ & $126.6 \pm 12.0$ & $123 \cdot 5 \pm 13.6$ & $<0.001$ \\
\hline $\mathrm{DBP}, \mathrm{mmHg}$ & $80.7 \pm 9.3$ & $83.4 \pm 8.6$ & $78.4 \pm 9 \cdot 3$ & $<0.001$ \\
\hline FPG, mg/dL & $104.1 \pm 14.2$ & $107 \cdot 1 \pm 14 \cdot 3$ & $101.6 \pm 13.6$ & $<0.001$ \\
\hline $2 \mathrm{hr}$ PG, mg/dL & $163.0 \pm 55 \cdot 3$ & $162.4 \pm 57.6$ & $163 \cdot 5 \pm 53 \cdot 3$ & 0.677 \\
\hline HbAıc, \% & $5 \cdot 9 \pm 0.5$ & $5 \cdot 9 \pm 0.5$ & $5.9 \pm 0.4$ & 0.058 \\
\hline Total cholesterol, mg/dL & $190.7 \pm 35.7$ & $189.4 \pm 37.1$ & $191.8 \pm 34.4$ & 0.183 \\
\hline Triglyceride, mg/dL & $148.8 \pm 92.6$ & $168.0 \pm 114.9$ & $132.7 \pm 64.3$ & $<0.001$ \\
\hline HDL-C, mg/dL & $51.6 \pm 13.4$ & $48.3 \pm 12.4$ & $54.4 \pm 13.6$ & $<0.001$ \\
\hline LDL-C, mg/dL & $117.9 \pm 33.8$ & $117.7 \pm 35.2$ & $118.1 \pm 32.6$ & 0.837 \\
\hline
\end{tabular}

Values are presented as mean \pm SD or number (\%).

BMI, body mass index; WC, waist circumference; DM, diabetes mellitus; SBP, systolic blood pressure; DBP, diastolic blood pressure; FPG, fasting plasma glucose; 2 hr PG, 2-hour postchallenge glucose; HbA1c, hemoglobin A1c; HDL-C, high density lipoprotein cholesterol; LDL-C, low density lipoprotein cholesterol.

Table 2. Proportion of pre-diabetes and diabetes by combination of diagnostic criteria

\begin{tabular}{lccccccc}
\hline Variable & $\begin{array}{c}\text { FPG } \\
\text { only }\end{array}$ & $\begin{array}{c}\text { 2hr } \\
\text { PG only }\end{array}$ & $\begin{array}{c}\text { HbAic } \\
\text { only }\end{array}$ & $\begin{array}{c}\text { FPG \& } \\
\text { 2hr PG }\end{array}$ & $\begin{array}{c}\text { FPG \& } \\
\text { HbAic }\end{array}$ & $\begin{array}{c}\text { 2hr PG \& } \\
\text { HbAic }\end{array}$ & $\begin{array}{c}\text { FPG \& 2hr } \\
\text { PG \& HbAic }\end{array}$ \\
\hline Normal & $664(40.5)$ & $659(40.3)$ & $504(30.8)$ & $389(23.8)$ & $317(19.4)$ & $310(18.9)$ & $220(13.5)$ \\
Prediabetes & $867(53.0)$ & $582(35.5)$ & $1,005(61.4)$ & $828(50.6)$ & $1,138(69.5)$ & $901(55.1)$ & $971(59.3)$ \\
Diabetes & $106(6.5)$ & $396(24.2)$ & $128(7.8)$ & $420(25.6)$ & $182(11.1)$ & $426(26.0)$ & $446(27.2)$ \\
\hline
\end{tabular}

Values are presented as number (\%).

FPG, fasting plasma glucose; 2 hr PG, 2-hour postchallenge glucose; HbAlc, hemoglobin Arc.

(FPG, 2hr PG, HbAic), the percentages of study participants with normal glucose tolerance (NGT) and prediabetes were $13.5 \%$ and $59.3 \%$, respectively. Among all participants, $446(27.2 \%)$ patients were newly diagnosed with diabetes according to the ADA criteria. We detected diabetes in 106 (6.5\%) participants using only FPG, 128 (7.8\%) using only $\mathrm{HbA1c}$, and 396 (24.2\%) using only 2hr PG (Table 2, Fig. 1). If the criteria were combined, the ADA criteria could best diagnose diabetes (27.2\%), as compared to the criteria of FPG + $2 \mathrm{hr}$ PG (25.6\%) and FPG + HbA1c (11.1\%) levels in overweight or obese subjects (Table 2). The kappa coefficient was 0.829 for FPG + 2 h PG, 0.631 for FPG + HbAlc, and 0.898 for $2 \mathrm{hr}$ PG + HbA1c (Supplementary Table 1).

We classified FPG levels into five categories from $<95$ $\mathrm{mg} / \mathrm{dL}$ to $\geq 126 \mathrm{mg} / \mathrm{dL}$ (< 95,95 to 99,100 to 109 , 110 to 125 , and $\geq 126 \mathrm{mg} / \mathrm{dL}$ ), including stage $1 \mathrm{IFG}$ (100 to 109 $\mathrm{mg} / \mathrm{dL}$ ) and stage $2 \mathrm{IFG}$ (110 to $125 \mathrm{mg} / \mathrm{dL}$ ) ranges (Table 
3). The prevalence of diabetes increased with an increase in FPG category $(p<0.001)$. Among the whole population, 867 subjects (52.9\%) demonstrated IFG (FPG, 100 to $125 \mathrm{mg} / \mathrm{dL})$, and 515 (31.4\%) and 352 (21.5\%) subjects were included in stage 1 and stage 2 IFG ranges, respectively. The $19.0 \%$ of subjects with stage 1 IFG and $43.5 \%$ with stage 2 IFG showed $2 \mathrm{hr}$ PG levels of $\geq 200 \mathrm{mg} / \mathrm{dL}$. In addition, of the 664 overweight and obese participants

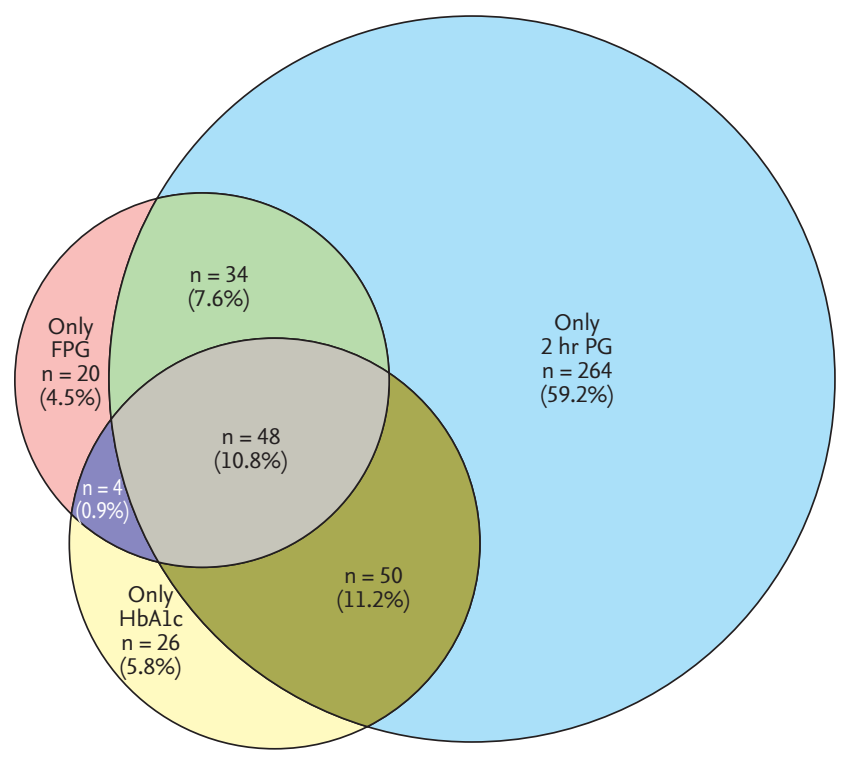

Figure 1. Proportional double Venn diagram. A proportional double Venn diagram has been used to quantify the distribution of fasting plasma glucose (FPG), 2-hour postchallenge glucose (2hr PG), and hemoglobin Aic (HbAic) for the 446 subjects with newly-diagnosed diabetes among the overweight and obese population in this study. with a normal fasting glucose concentration $(\leq 100 \mathrm{mg} /$ $\mathrm{dL}), 63$ patients $(9.5 \%)$ had diabetes $(2 \mathrm{hr} \mathrm{PG} \geq 200 \mathrm{mg} /$ $\mathrm{dL}$ ). When we lowered the FPG level to $95 \mathrm{mg} / \mathrm{dL}, 7.4 \%$ of subjects with FPG of $<95 \mathrm{mg} / \mathrm{dL}$ range and $12.6 \%$ with FPG of 95 to $99 \mathrm{mg} / \mathrm{dL}$ range were determined to have diabetes $(2 \mathrm{hr} P G \geq 200 \mathrm{mg} / \mathrm{dL}$ ) (Table 3 ).

Mean HbAic and BMI levels of subjects with stage 1 and 2 IFG were $5.8 \% \pm 0.4 \%$ versus $6.1 \% \pm 0.4 \%(p<$ $0.001)$ and $26.5 \pm 2.9 \mathrm{~kg} / \mathrm{m}^{2}$ versus $26.5 \pm 2.5 \mathrm{~kg} / \mathrm{m}^{2}(p=$ 0.003), respectively. Compared to the subjects with NGT, participants with IFG were more likely to be male, and had a higher BMI as well as higher systolic and diastolic BP levels. In addition, compared to subjects with stage 1 IFG, the mean systolic BP was higher in stage 2 IFG subjects (Table 4).

When we classified the study population into 3 BMI categories $\left(23.0 \leq \mathrm{BMI}<25.0 \mathrm{~kg} / \mathrm{m}^{2} ; 25.0 \leq \mathrm{BMI}<27.0 \mathrm{~kg} /\right.$ $\left.\mathrm{m}^{2}, \mathrm{BMI} \geq 27.0 \mathrm{~kg} / \mathrm{m}^{2}\right)$, mean FPG and $2 \mathrm{hr}$ PG levels and a proportion of subjects with a family history of diabetes or hypertension were highest in the higher BMI group. By HbA1c definition, 7.1\%, 7.2\%, and 9.2\% of subjects were classified as having diabetes, respectively. However, $18.5 \%, 29.0 \%$, and $26.2 \%$ of participants were diagnosed with diabetes by $2 \mathrm{hr}$ PG criteria (Supplementary Table 2).

Even in overweight individuals with a normal fasting glucose level $(<100 \mathrm{mg} / \mathrm{dL}), 5.9 \%$ of subjects were diagnosed as having diabetes by the $2 \mathrm{hr}$ PG criteria. The $17.7 \%$ and $35.8 \%$ of overweight subjects with stage 1 and stage 2 were classified as having diabetes, respectively (Supplementary Table 3).

Table 3. Comparison of the FPG and $2 \mathrm{hr}$ PG criteria for the diagnosis of diabetes

\begin{tabular}{|c|c|c|c|c|c|c|}
\hline \multirow{2}{*}{ Variable } & \multicolumn{4}{|c|}{ 2hr PG, mg/dL } & \multirow{2}{*}{$\mathrm{DM}, \%^{\mathrm{a}}$} & \multirow{2}{*}{$p$ value } \\
\hline & $<140$ & $140-199$ & $\geq 200$ & Total & & \\
\hline FPG, mg/dL & & & & & & $<0.001$ \\
\hline$<95$ & $255(15.6)$ & $110(6.7)$ & $29(1.8)$ & $394(24.1)$ & $7 \cdot 4$ & \\
\hline $95-99$ & $134(8.2)$ & $102(6.2)$ & $34(2.1)$ & $270(16.5)$ & 12.6 & \\
\hline $100-109$ & $205(12.5)$ & $212(13.0)$ & $98(6.0)$ & $515(31.4)$ & 19.0 & \\
\hline $110-125$ & $58(3.5)$ & $141(8.6)$ & $153(9 \cdot 4)$ & $352(21.5)$ & $43 \cdot 5$ & \\
\hline$\geq 126$ & $7(0.4)$ & $17(1.0)$ & $82(5.0)$ & $106(6.5)$ & 100.0 & \\
\hline Total & $659(40.2)$ & $582(35 \cdot 6)$ & $396(24.2)$ & $1,637(100.0)$ & $25 \cdot 7$ & \\
\hline
\end{tabular}

Values are presented as number (\%).

FPG, fasting plasma glucose; 2 hr PG, 2-hr postchallenge glucose; DM, diabetes mellitus.

${ }^{a}$ The prevalence of diabetes based on $2 \mathrm{hr}$ PG level of $\geq 200 \mathrm{mg} / \mathrm{dL}$ according to FPG category $(<95,95-99,100-109,110-125$, and $\geq 126 \mathrm{mg} / \mathrm{dL}$ ). 
Table 4. Clinical characteristics of subjects with IFG according to IGT

\begin{tabular}{|c|c|c|c|c|}
\hline Characteristic & $\begin{array}{c}\text { NGT } \\
\text { FPG }<100 \mathrm{mg} / \mathrm{dL} \\
(\mathrm{n}=664)\end{array}$ & $\begin{array}{c}\text { Stage } 1 \\
100 \leq \mathrm{FPG}<110 \mathrm{mg} / \mathrm{dL} \\
(\mathrm{n}=515)\end{array}$ & $\begin{array}{c}\text { Stage 2 } \\
110 \leq \mathrm{FPG}<126 \mathrm{mg} / \mathrm{dL} \\
(\mathrm{n}=352)\end{array}$ & $p$ value \\
\hline Age, yr & $54.7 \pm 8.2$ & $55.2 \pm 8.5$ & $55 \cdot 5 \pm 7 \cdot 4$ & 0.308 \\
\hline Male sex & $236(35 \cdot 5)$ & $245(47 \cdot 6)$ & $199(56.5)$ & $<0.001$ \\
\hline Height, cm & $161.1 \pm 8.6$ & $163.1 \pm 8.5^{\mathrm{a}}$ & $164.4 \pm 9.1^{\mathrm{a}}$ & $<0.001$ \\
\hline Weight, kg & $67.8 \pm 10.1$ & $70.7 \pm 10.7^{\mathrm{a}}$ & $71.9 \pm 10.5^{\mathrm{a}}$ & $<0.001$ \\
\hline $\mathrm{BMI}, \mathrm{kg} / \mathrm{m}^{2}$ & $26.0 \pm 2.7$ & $26.5 \pm 2.9^{\mathrm{a}}$ & $26.5 \pm 2.5^{\mathrm{a}}$ & 0.003 \\
\hline $\mathrm{WC}, \mathrm{cm}$ & $89.4 \pm 7.9$ & $90.8 \pm 8.5^{\mathrm{a}}$ & $91.6 \pm 7.5^{\mathrm{a}}$ & $<0.001$ \\
\hline $\mathrm{SBP}, \mathrm{mmHg}$ & $122.9 \pm 12.8$ & $125.2 \pm 13.1^{\mathrm{a}}$ & $127.6 \pm 12.9^{\mathrm{a}, \mathrm{b}}$ & $<0.001$ \\
\hline $\mathrm{DBP}, \mathrm{mmHg}$ & $79.9 \pm 9.3$ & $80.6 \pm 9.2$ & $81.7 \pm 9.5^{\mathrm{a}}$ & 0.011 \\
\hline FPG, mg/dL & $92.2 \pm 5.4$ & $104.3 \pm 2.9^{\mathrm{a}}$ & $116.0 \pm 4 \cdot 6^{\mathrm{a}, \mathrm{b}}$ & $<0.001$ \\
\hline 2hr PG, mg/dL & $138.8 \pm 41.2$ & $158.0 \pm 45 \cdot 3^{\mathrm{a}}$ & $191.5 \pm 53.8^{\mathrm{a}, \mathrm{b}}$ & $<0.001$ \\
\hline $\mathrm{HbAic}, \%$ & $5.7 \pm 0.3$ & $5.8 \pm 0.4^{\mathrm{a}}$ & $6.1 \pm 0.4^{\mathrm{a}, \mathrm{b}}$ & $<0.001$ \\
\hline $\mathrm{TC}, \mathrm{mg} / \mathrm{dL}$ & $188.5 \pm 34.8$ & $191.6 \pm 35.0$ & $192.5 \pm 37.6$ & 0.169 \\
\hline $\mathrm{TG}, \mathrm{mg} / \mathrm{dL}$ & $141.3 \pm 98.2$ & $148.3 \pm 86.7$ & $153 \cdot 3 \pm 74.5^{\mathrm{a}}$ & $<0.001$ \\
\hline HDL-C, mg/dL & $52.2 \pm 13.2$ & $52.3 \pm 14.3$ & $50.9 \pm 12.4$ & 0.279 \\
\hline LDL-C, mg/dL & $116.4 \pm 33.3$ & $118.6 \pm 32.9$ & $119.1 \pm 35.7$ & 0.387 \\
\hline $2 \mathrm{hr} P G \geq 200 \mathrm{mg} / \mathrm{dL}$ & $63(9.5)$ & $98(19.0)$ & $153(43 \cdot 5)$ & $<0.001$ \\
\hline $\mathrm{HbA1c} \geq 6.5 \%$ & $7(1.1)$ & $18(3 \cdot 5)$ & $51(14 \cdot 5)$ & $<0.001$ \\
\hline \multicolumn{5}{|l|}{ Alcohol drinking } \\
\hline None & $272(41.0)$ & $207(40.2)$ & $126(35.8)$ & 0.570 \\
\hline Ex & $30(4 \cdot 5)$ & $25(4.9)$ & $16(4 \cdot 5)$ & \\
\hline Current & $362(54 \cdot 5)$ & $283(54 \cdot 9)$ & $210(59.7)$ & \\
\hline g/day & $19 \cdot 5 \pm 34 \cdot 5$ & $20.3 \pm 23.2$ & $24.4 \pm 30.5^{\mathrm{a}}$ & 0.001 \\
\hline \multicolumn{5}{|l|}{ Smoking } \\
\hline None & $463(69.7)$ & $317(61.5)$ & $185(52.6)$ & $<0.001$ \\
\hline Ex & $132(19.9)$ & $143(27.8)$ & $117(33.2)$ & \\
\hline Current & $69(10.4)$ & $55(10.7)$ & $50(14.2)$ & \\
\hline Pack-years & $18.5 \pm 13.5$ & $19.7 \pm 15.9$ & $23.0 \pm 16.2^{\mathrm{a}, \mathrm{b}}$ & 0.008 \\
\hline
\end{tabular}

Values are presented as mean \pm SD or number (\%). Nonparametric statistical tests were done for HbA1c, TG, PG\%, alcohol intake and pack-years. Post hoc tests were done using Sheffe method.

IFG, impaired fasting glucose; IGT, impaired glucose tolerance; NGT, normal glucose tolerance; FPG, fasting plasma glucose; BMI, body mass index; WC, waist circumference; SBP, systolic blood pressure; DBP, diastolic blood pressure; 2hr PG, 2-hour postchallenge glucose; HbA1c, hemoglobin A1c; TC, total cholesterol; TG, triglyceride; HDL-C, high density lipoprotein cholesterol; LDL-C, low density lipoprotein cholesterol.

${ }^{\mathrm{a}}<0.05$ vs. NGT.

${ }^{\mathrm{b}}<0.05$ vs. Stage 1 .

\section{DISCUSSION}

According to this population-based study recently performed among Korean adults with a high risk of diabetes, we found that overweight or obese individuals (BMI $\geq 23.0 \mathrm{~kg} / \mathrm{m}^{2}$ ) with an IFG range (FPG, 100 to $125 \mathrm{mg} /$ $\mathrm{dL}$ ) should undergo an OGTT to exclude a diagnosis of diabetes. Without an OGTT, 19.0\% of stage 1 and $43.5 \%$ of stage 2 IFG participants were not diagnosed with diabetes, and thus prompt intervention may be delayed for 
these overweight or obese individuals. Moreover, 9.5\% of the population with a normal FPG level $(<100 \mathrm{mg} /$ $\mathrm{dL}$ ) showed a $2 \mathrm{hr} P G \geq 200 \mathrm{mg} / \mathrm{dL}$. Therefore, the active screening cut-off for the detection of diabetes in overweight or obese Korean adult individuals should be FPG value of $\geq 100 \mathrm{mg} / \mathrm{dL}$.

Prediabetes is a long-term disorder, and thus there is sufficient time to perform an early diagnosis and intervention. In addition, although the condition may be reversible, it is associated with an increased risk of CVD $[15,16]$. An increasing number of patients with T2DM emphasizes the need for active screening of high-risk individuals and intensive lifestyle modification [17-19]. When considering data on prediabetes with no targeted intervention, the annual incidence of progression from prediabetes to $\mathrm{T} 2 \mathrm{DM}$ is $5 \%$ to $10 \%$ [20].

Over the past 7 years, the prevalence of obesity $(\mathrm{BMI} \geq$ $25.0 \mathrm{~kg} / \mathrm{m}^{2}$ ) in the Korean population aged 20 years and older has increased steadily from $29.7 \%$ in 2009 to $32.4 \%$ in 2015 , and the prevalence of abdominal obesity also increased from $18.4 \%$ in 2009 to $20.8 \%$ in 2015 [21]. With a continuous increase in the prevalence of obesity in individuals aged between 20 and 60 years, the incidence of $\mathrm{T} 2 \mathrm{DM}$ also increased even from the lowest level of BMI [21]. Although being overweight or obese is a very important comorbidity and risk factor for T2DM, BMI has not yet been considered as a screening tool for T2DM. Only FPG and HbAic levels have been considered as screening tests for diabetes. If a simple and easily measurable clinical variable is combined with FPG and $\mathrm{HbAlc}$ measurement when screening for $\mathrm{T}_{2} \mathrm{DM}$, more patients with diabetes could be detected without delay. From this point of view, BMI or waist circumference among other anthropometric parameters could be an appropriate and effective clinical factor for this purpose [22].

Current recommendations to screen for diabetes are inconsistent across different guidelines. According to the ADA recommendation, testing for prediabetes and risk for future diabetes in asymptomatic people should be considered in adults of any age who are overweight or obese (BMI $\geq 25.0$ or $\geq 23.0 \mathrm{~kg} / \mathrm{m}^{2}$ for Asian Americans) and those who have $\geq 1$ additional risk factors for diabetes [14]. According to the Japan Diabetes Society (JDS), the IFG category is defined as FPG levels of 110 to $125 \mathrm{mg} / \mathrm{dL}$, and an FPG range of 100 to $109 \mathrm{mg} / \mathrm{dL}$ is classified into the 'high normal' category, falling within normal levels.
However, subjects with a high-normal glucose level are at risk for developing diabetes and represent various degrees of IFG. Therefore, the OGTT is proactively considered for high-risk individuals (HbAlc $\geq 5.6 \%$, obesity, dyslipidemia, family history of diabetes) [23].

The FPG cut-off values are far from being equivalent to their corresponding $2 \mathrm{hr}$ PG values [24]. In fact, the majority of subjects with FPG $\geq 100 \mathrm{mg} / \mathrm{dL}$ display normal or non-diabetic 2 hr PG. More importantly, a consistent proportion of subjects with IGT display an FPG level $\leq 100 \mathrm{mg} / \mathrm{dL}[25,26]$. Furthermore, in longitudinal epidemiological studies, around $40 \%$ of subjects who develop T2DM exhibit NGT at baseline blood glucose testing, indicating that there is a large number of NGT subjects who constitute the larger pool of future $\mathrm{T} 2 \mathrm{DM}$ populations [27].

Since there is a large discordance rate in the diagnosis of diabetes and IGT using the FPG and $2 \mathrm{hr}$ PG criteria, the CPG of the KDA has classified subjects with IFG into two stages according to their FPG levels (stage 1 IFG [100 to $109 \mathrm{mg} / \mathrm{dL}$ ] and stage 2 IFG [110 to $125 \mathrm{mg} / \mathrm{dL}$ ]) to screen for those with a high risk of diabetes in the general population during the last decade [28]. This classification was based on four population-based studies conducted from 1993 to 2000 [29]. Their mean age and BMI levels were 52.1 years and $23.8 \mathrm{~kg} / \mathrm{m}^{2}$, respectively. From the analysis, seven times more individuals with stage 2 IFG were diagnosed with diabetes as determined by $2 \mathrm{hr}$ PG, compared to stage 1 IFG in the general population (14.1\% vs. 1.9\%, $p<0.05$ ). Based on the previous report, individuals with stage 2 IFG should be treated differently from those with stage 1 IFG. To detect more cases of diabetes, the OGTT is recommended for all individuals with stage 2 IFG as well as for cases with stage 1 IFG with some additional risk factors for diabetes.

Compared to a previous KDA report performed approximately 20 years ago, this recent study showed remarkable and important findings on the screening of diabetes. In the general population, the prevalence of diabetes in the normal FPG range $(<100 \mathrm{mg} / \mathrm{dL})$ and stage 1 IFG was $1.2 \%$ and $1.9 \%$, respectively. However, in the overweight or obese population, the corresponding proportions were $9.5 \%$ and $19.0 \%$, respectively. Moreover, $43.5 \%$ of stage 2 IFG subjects were diagnosed with diabetes based on the $2 \mathrm{hr}$ PG criteria. From this result, we suggest that classification of stage 1 or 2 IFG does not have 
much meaning in the screening of diabetes in overweight or obese Korean individuals with IFG. Moreover, the FPG cutoff needs to be lower than $100 \mathrm{mg} / \mathrm{dL}$ in individuals who are overweight or obese. Even in subjects with FPG < $95 \mathrm{mg} / \mathrm{dL}, 7.4 \%$ of overweight or obese subjects were not diagnosed as having diabetes without an OGTT.

Korea has a national health screening examination service provided by the National Health Insurance Service, and adults aged 40 years and older have the opportunity to check their FPG concentration. Although the recommended screening measure for prediabetes consists of FPG, HbAic, and the 2 hr PG after OGTT, OGTT sampling is not feasible as a routine health check-up. However, the OGTT should be actively considered for Korean adults who are overweight or obese to allow for early detection of diabetes and prompt intervention.

There were some limitations in this study. First, glucose tolerance was determined on only one occasion. This could lead to a misclassification of glucose tolerance. We believe that such misclassification would affect all categories of glucose tolerance equally. Second, the prevalence of diabetes was calculated only by FPG and 2hr PG criteria, and the HbArc level was not considered. In spite of this limitation, this study suggested that the FPG levels for the screening of diabetes should be lowered in overweight or obese individuals.

In conclusion, the prevalence and incidence of $\mathrm{T} 2 \mathrm{DM}$ and obesity are steadily increasing in Korea, especially in young and middle-aged adults. To prevent a progression from prediabetes to $\mathrm{T} 2 \mathrm{DM}$, active screening with OGTT is needed in overweight or obese individuals with an FPG level of $\geq 100 \mathrm{mg} / \mathrm{dL}$. Further investigation on the cutoff level of FPG in this group for the early detection of diabetes is warranted.

\section{KEY MESSAGE}

1. Overweight or obese individuals (body mass index $\geq 23.0 \mathrm{~kg} / \mathrm{m}^{2}$ ) with an impaired glucose tolerance range (fasting plasma glucose [FPG], 100 to $125 \mathrm{mg} / \mathrm{dL}$ ) should undergo an oral glucose tolerance test to exclude a diagnosis of diabetes.

2. Active screening with $75 \mathrm{~g}$ oral glucose tolerance test is required in overweight or obese individuals with an FPG level of $\geq 100 \mathrm{mg} / \mathrm{dL}$ to search for the presence of diabetes.

\section{Conflict of interest}

No potential conflict of interest relevant to this article was reported.

\section{Acknowledgments}

This study was funded by the Korean Health Technology R\&D Project, Ministry of Health and Welfare, Republic of Korea ( $\left.\mathrm{HC}_{15} \mathrm{C}_{33} 64\right)$. The research team would like to thank the Korean Diabetes Association, and two healthcare centers of Chungju city and Paldal-gu, Suwon, Korea.

The full list of all participating university hospitals and contributors is as follows: Korean Diabetes Prevention Study. Moon-Kyu Lee (Department of Medicine, Samsung Medical Center, Sungkyunkwan University School of Medicine, Seoul, Korea), Kyong Soo Park (Department of Internal Medicine, Seoul National University College of Medicine, Seoul, Korea), Bong Soo Cha (Department of Internal Medicine, Yonsei University College of Medicine, Seoul, Korea), Sei-Hyun Baik (Division of Endocrinology and Metabolism, Department of Internal Medicine, Korea University Medical Center, Korea University College of Medicine, Seoul, Korea), Joong Yeol Park (Department of Internal Medicine, Asan Medical Center, University of Ulsan College of Medicine, Seoul, Korea), Kwan Woo Lee (Department of Endocrinology and Metabolism, Ajou University School of Medicine, Suwon, Korea), In-Kyu Lee (Division of Endocrinology and Metabolism, Department of Internal Medicine, Kyungpook National University School of Medicine, Daegu), Tae Sun Park (Department of Internal Medicine, Chonbuk National University Hospital, Chonbuk National University Medical School, Jeonju, Korea), In Joo Kim (Department of Nuclear Medicine and Biomedical Research Institute, Pusan National University Hospital, Pusan National University School of Medicine, Busan, Korea), Young Jung Cho (Department of Internal Medicine, National Medical Center, Seoul), Dong Hyeok Cho (Division of Endocrinology and Metabolism, Department of Internal Medicine, Chonnam National University Hospital, Chonnam National University Medical School, Gwangju, Korea), Sung Wan 
Chun (Department of Internal Medicine, Soonchunhyang University Cheonan Hospital, Soonchunhyang University College of Medicine, Cheonan, Korea), So Hun Kim (Department of Internal Medicine, Inha University School of Medicine, Incheon, Korea), Seo Young Sohn (Division of Endocrinology, Department of Medicine, Myongji Hospital, Goyang, Korea), You Cheol Hwang (Department of Endocrinology and Metabolism, KyungHee University Hospital at Gangdong, Kyung-Hee University School of Medicine, Seoul, Korea), Eunjeong Kang (Department of Endocrinology and Metabolism, Kyung Hee University Hospital, Kyung Hee University School of Medicine, Seoul, Korea), and Jihye Choi (Department of Endocrinology and Metabolism, Kyung Hee University Hospital, Kyung Hee University School of Medicine, Seoul, Korea).

\section{REFERENCES}

1. Korean Diabetes Association. Korean diabetes fact sheet 2018 [Internet]. Seoul (KR): Korean Diabetes Association, 2018 [cited 2019 Nov 26]. Available from: http://www.diabetes.or.kr/english/.

2. Knowler WC, Barrett-Connor E, Fowler SE, et al. Reduction in the incidence of type 2 diabetes with lifestyle intervention or metformin. N Engl J Med 2002;346:393-403.

3. de Vegt F, Dekker JM, Jager A, et al. Relation of impaired fasting and postload glucose with incident type 2 diabetes in a Dutch population: the Hoorn Study. JAMA 2001;285:2109-2113.

4. Bergman M, Buysschaert M, Schwarz PE, Albright A, Narayan KV, Yach D. Diabetes prevention: global health policy and perspectives from the ground. Diabetes Manag (Lond) 2012;2:309-321.

5. Report of the expert committee on the diagnosis and classification of diabetes mellitus. Diabetes Care 1997;20:11831197.

6. Parappil A, Doi SA, Al-Shoumer KA. Diagnostic criteria for diabetes revisited: making use of combined criteria. BMC Endocr Disord 2002;2:1.

7. Narayan KM, Imperatore G, Benjamin SM, Engelgau MM. Targeting people with pre-diabetes. BMJ 2002;325:403404.

8. Perreault L, Bergman BC, Playdon MC, Dalla Man C, Cobelli C, Eckel RH. Impaired fasting glucose with or without impaired glucose tolerance: progressive or parallel states of prediabetes? Am J Physiol Endocrinol Metab 2008;295:E428-E435.

9. Janghorbani M, Amini M. Comparison of fasting glucose with post-load glucose values and glycated hemoglobin for prediction of type 2 diabetes: the Isfahan diabetes prevention study. Rev Diabet Stud 2009;6:117-123.

10. Bao C, Zhang D, Sun B, et al. Optimal cut-off points of fasting plasma glucose for two-step strategy in estimating prevalence and screening undiagnosed diabetes and pre-diabetes in Harbin, China. PLoS One 2015;10:e0119510.

11. Committee of Clinical Practice Guideline of Korean Diabetes Association. 2015 Treatment guideline for diabetes [Internet]. Seoul (KR): Korean Diabetes Association, c2011 [cited 2019 Nov 26]. Available from: http://www.diabetes. or.kr/pro/publish/guide.php?code=guide\&year_v=2015\&mode=view\&number $=625 /$.

12. Cha SA, Lim SY, Kim KR, et al. Community-based randomized controlled trial of diabetes prevention study for high-risk individuals of type 2 diabetes: lifestyle intervention using web-based system. BMC Public Health 2017;17:387-395.

13. Rhee SY, Chon S, Ahn KJ, Woo JT; Korean Diabetes Prevention Study Investigators. Hospital-based Korean diabetes prevention study (H-KDPS): a prospective, multi-center, randomized, open-label controlled study. Diabetes Metab J 2019;43:49-58.

14. American Diabetes Association. 2. Classification and diagnosis of diabetes: standards of medical care in diabetes-2018. Diabetes Care 2018;41(Suppl 1):S13-S27.

15. Huang Y, Cai X, Mai W, Li M, Hu Y. Association between prediabetes and risk of cardiovascular disease and all cause mortality: systematic review and meta-analysis. BMJ 2016;355:15953.

16. Park C, Guallar E, Linton JA, et al. Fasting glucose level and the risk of incident atherosclerotic cardiovascular diseases. Diabetes Care 2013;36:1988-1993.

17. Diabetes Prevention Program (DPP) Research Group. The Diabetes Prevention Program (DPP): description of lifestyle intervention. Diabetes Care 2002;25:2165-2171.

18. Diabetes Prevention Program Research Group, Knowler WC, Fowler SE, et al. 10-Year follow-up of diabetes incidence and weight loss in the Diabetes Prevention Program Outcomes Study. Lancet 2009;374:1677-1686.

19. Lindstrom J, Ilanne-Parikka P, Peltonen M, et al. Sus- 
tained reduction in the incidence of type 2 diabetes by lifestyle intervention: follow-up of the Finnish Diabetes Prevention Study. Lancet 2006;368:1673-1679.

20. DeJesus RS, Breitkopf CR, Rutten LJ, Jacobson DJ, Wilson $\mathrm{PM}$, Sauver JS. Incidence rate of prediabetes progression to diabetes: modeling an optimum target group for intervention. Popul Health Manag 2017;20:216-223.

21. Seo MH, Kim YH, Han K, et al. Prevalence of obesity and incidence of obesity-related comorbidities in Koreans based on national health insurance service health checkup data 2006-2015. J Obes Metab Syndr 2018;27:46-52.

22. Lee YH, Bang H, Kim HC, Kim HM, Park SW, Kim DJ. A simple screening score for diabetes for the Korean population: development, validation, and comparison with other scores. Diabetes Care 2012;35:1723-1730.

23. Haneda M, Noda M, Origasa $H$, et al. Japanese clinical practice guideline for diabetes 2016. Diabetol Int 2018;9:145.

24. DECODE Study Group on behalf of the European Diabetes Epidemiology Study Group. Will new diagnostic cri- teria for diabetes mellitus change phenotype of patients with diabetes? Reanalysis of European epidemiological data. BMJ 1998;317:371-375.

25. Tai ES, Goh SY, Lee JJ, et al. Lowering the criterion for impaired fasting glucose: impact on disease prevalence and associated risk of diabetes and ischemic heart disease. Diabetes Care 2004;27:1728-1734.

26. Tuomilehto J. Point: a glucose tolerance test is important for clinical practice. Diabetes Care 2002;25:1880-1882.

27. Unwin N, Shaw J, Zimmet P, Alberti KG, Alberti KG. Impaired glucose tolerance and impaired fasting glycaemia: the current status on definition and intervention. Diabet Med 2002;19:708-723.

28. Kim MK, Ko SH, Kim BY, et al. 2019 Clinical practice guidelines for type 2 diabetes mellitus in Korea. Diabetes Metab J 2019;43:398-406.

29. Oh JY, Lim S, Kim DJ, et al. A report on the diagnosis of intermediate hyperglycemia in Korea: a pooled analysis of four community-based cohort studies. Diabetes Res Clin Pract 2008;80:463-468. 
KJIM'

The Korean Journal of Internal Medicine Vol. 36, No. 2, March 2021

Supplementary Table 1. Kappa statistic $(\kappa)$ according to diabetes diagnosis criteria

\begin{tabular}{|c|c|c|c|c|c|c|c|}
\hline Variable & $\begin{array}{l}\text { FPG } \\
\text { only }\end{array}$ & $\begin{array}{c}\text { 2hr PG } \\
\text { only }\end{array}$ & $\begin{array}{c}\text { HbAic } \\
\text { only }\end{array}$ & $\begin{array}{c}\text { FPG \& } 2 h r \\
\text { PG }\end{array}$ & $\begin{array}{l}\text { FPG \& } \\
\text { HbAlc }\end{array}$ & $\begin{array}{c}\text { 2hr PG \& } \\
\text { HbAic }\end{array}$ & $\begin{array}{c}\text { FPG \& } 2 \text { hrPG } \\
\text { \& HbAic }\end{array}$ \\
\hline FPG only & 1.000 & 0.287 & 0.320 & 0.512 & 0.572 & 0.254 & 0.346 \\
\hline 2hr PG only & & 1.000 & 0.285 & 0.781 & 0.297 & 0.716 & o. 631 \\
\hline HbAic only & & & 1.000 & 0.298 & 0.734 & 0.557 & 0.449 \\
\hline FPG \& $2 h r$ PG & & & & 1.000 & 0.477 & 0.741 & 0.829 \\
\hline FPG \& HbAic & & & & & 1.000 & 0.538 & 0.631 \\
\hline 2hr PG \& HbAic & & & & & & 1.000 & 0.898 \\
\hline FPG \& 2 hr PG \& HbAlc & & & & & & & 1.000 \\
\hline
\end{tabular}

FPG, fasting plasma glucose; 2hr PG, 2-hour postchallenge glucose; HbArc, hemoglobin Aic. 
Supplementary Table 2. Clinical characteristics of subjects with impaired fasting glucose according to BMI categories

\begin{tabular}{|c|c|c|c|c|}
\hline Characteristic & $\begin{array}{c}23.0 \leq \mathrm{BMI}<25.0 \mathrm{~kg} / \mathrm{m}^{2} \\
(\mathrm{n}=604)\end{array}$ & $\begin{array}{c}25.0 \leq \mathrm{BMI}<27.0 \mathrm{~kg} / \mathrm{m}^{2} \\
(\mathrm{n}=487)\end{array}$ & $\begin{array}{c}\mathrm{BMI}<27.0 \mathrm{~kg} / \mathrm{m}^{2} \\
\quad(\mathrm{n}=546)\end{array}$ & $p$ value \\
\hline Age, yr & $55.8 \pm 7.6$ & $55.8 \pm 7.5$ & $53.4 \pm 9.0$ & $<0.001$ \\
\hline Male sex & $253(41.9)$ & $245(50.3)$ & $254(46.5)$ & 0.020 \\
\hline Height, cm & $162.1 \pm 8.6$ & $163.3 \pm 8.8$ & $163.0 \pm 9.0$ & 0.063 \\
\hline Weight, kg & $63.0 \pm 6.9$ & $69.2 \pm 7.6$ & $78.5 \pm 10.2$ & $<0.001$ \\
\hline $\mathrm{BMI}, \mathrm{kg} / \mathrm{m}^{2}$ & $23.9 \pm 0.6$ & $25.9 \pm 0.6$ & $29.5 \pm 2.3$ & $<0.001$ \\
\hline WC, cm & $84.9 \pm 5.8$ & $90.0 \pm 5.0$ & $97.2 \pm 7.4$ & $<0.001$ \\
\hline $\mathrm{SBP}, \mathrm{mmHg}$ & $121.9 \pm 12.7$ & $125.0 \pm 13.1$ & $128.1 \pm 12.5$ & $<0.001$ \\
\hline $\mathrm{DBP}, \mathrm{mmHg}$ & $78.3 \pm 9.5$ & $81.1 \pm 8.6$ & $83.0 \pm 9.1$ & $<0.001$ \\
\hline FPG, mg/dL & $102.1 \pm 13.3$ & $104 \cdot 4 \pm 13 \cdot 3$ & $106.1 \pm 15.5$ & $<0.001$ \\
\hline $2 \mathrm{hr}$ PG, mg/dL & $156.6 \pm 52.7$ & $165.2 \pm 58.6$ & $168.2 \pm 54.5$ & 0.001 \\
\hline HbAlc, \% & $5.8 \pm 0.5$ & $5.9 \pm 0.4$ & $5.9 \pm 0.5$ & 0.034 \\
\hline $\mathrm{TC}, \mathrm{mg} / \mathrm{dL}$ & $190.8 \pm 35.4$ & $189.0 \pm 35.0$ & $192.0 \pm 36.6$ & 0.415 \\
\hline $\mathrm{TG}, \mathrm{mg} / \mathrm{dL}$ & $133.9 \pm 89.7$ & $152.5 \pm 92.7$ & $162.2 \pm 93.4$ & $<0.001$ \\
\hline HDL-C, mg/dL & $53 \cdot 4 \pm 14.2$ & $51.5 \pm 13.4$ & $49.7 \pm 12.1$ & $<0.001$ \\
\hline LDL-C, mg/dL & $118.6 \pm 33.6$ & $116.0 \pm 33.5$ & $118.7 \pm 34.1$ & 0.368 \\
\hline Alcohol drinker & $318(52.7)$ & $284(58.3)$ & $328(60.1)$ & 0.025 \\
\hline Current smoker & $59(9.8)$ & $67(13.8)$ & $72(13.2)$ & 0.025 \\
\hline $\mathrm{F} / \mathrm{Hx}$ of DM & $256(42.7)$ & $211(43.6)$ & $256(47.2)$ & 0.279 \\
\hline Hypertension & $135(22.4)$ & $146(30.0)$ & $200(36.6)$ & $<0.001$ \\
\hline \multicolumn{5}{|l|}{ FPG levels, mg/dL } \\
\hline$<100$ & $286(47 \cdot 3)$ & $187(38.4)$ & $191(35.0)$ & 0.001 \\
\hline $100-109$ & $181(30.0)$ & $154(31.6)$ & $180(33.0)$ & \\
\hline $110-125$ & $106(17.6)$ & $114(23.4)$ & $132(24.2)$ & \\
\hline$\geq 126$ & $31(5.1)$ & $32(6.6)$ & $43(7.8)$ & \\
\hline $2 \mathrm{hr} P G \geq 200 \mathrm{mg} / \mathrm{dL}$ & $112(18.5)$ & $141(29.0)$ & $143(26.2)$ & 0.001 \\
\hline $\mathrm{HbA1c} \geq 6.5 \%$ & $43(7.1)$ & $35(7.2)$ & $50(9.2)$ & 0.024 \\
\hline
\end{tabular}

Values are presented as mean $\pm \mathrm{SD}$ or number (\%).

BMI, body mass index; WC, waist circumference; SBP, systolic blood pressure; DBP, diastolic blood pressure; FPG, fasting plasma glucose; 2hr PG, 2-hour postchallenge glucose; HbAlc, hemoglobin Alc; TC, total cholesterol; TG, triglyceride; HDL-C, high density lipoprotein cholesterol; LDL-C, low density lipoprotein cholesterol; F/Hx, family history;; DM, diabetes mellitus; FPG, fasting plasma glucose. 
Supplementary Table 3. Comparison of the FPG and $2 \mathrm{hr}$ PG criteria for the diagnosis of diabetes according to BMI categories

\begin{tabular}{|c|c|c|c|c|c|}
\hline \multirow{2}{*}{ FPG, mg/dL } & \multicolumn{4}{|c|}{$2 \mathrm{hr}$ PG, mg/dL } & \multirow{2}{*}{$\mathrm{DM}, \%$} \\
\hline & $<140$ & $140-199$ & $\geq 200$ & Total & \\
\hline \multicolumn{6}{|c|}{$23.0 \leq \mathrm{BMI}<25.0 \mathrm{~kg} / \mathrm{m}^{2}(\mathrm{n}=604)$} \\
\hline$<100$ & 28.6 & 15.9 & 2.8 & $47 \cdot 4$ & 5.9 \\
\hline $100-109$ & 12.7 & 11.9 & $5 \cdot 3$ & 30.0 & 17.7 \\
\hline $110-125$ & $3 \cdot 5$ & 7.8 & 6.3 & 17.5 & 35.8 \\
\hline$\geq 126$ & 0.2 & 0.8 & 4.1 & $5 \cdot 1$ & 100 \\
\hline \multicolumn{6}{|c|}{$25.0 \leq \mathrm{BMI}<27.0 \mathrm{~kg} / \mathrm{m}^{2}(\mathrm{n}=487)$} \\
\hline$<100$ & 22.6 & 9.9 & 6.0 & 38.4 & $15 \cdot 5$ \\
\hline $100-109$ & 11.3 & 12.9 & $7 \cdot 4$ & 31.6 & $23 \cdot 4$ \\
\hline $110-125$ & 4.1 & 8.8 & 10.5 & $23 \cdot 4$ & $44 \cdot 7$ \\
\hline$\geq 126$ & 0.5 & 1.2 & 5.1 & 6.6 & 100 \\
\hline \multicolumn{6}{|c|}{$\mathrm{BMI} \geq 27.0 \mathrm{~kg} / \mathrm{m}^{2}(\mathrm{n}=546)$} \\
\hline$<100$ & 19.4 & 12.5 & 3.1 & $35 \cdot 0$ & 8.9 \\
\hline $100-109$ & $13 \cdot 4$ & 14.1 & $5 \cdot 5$ & 33.0 & 16.7 \\
\hline $110-125$ & 3.1 & $9 \cdot 3$ & 11.7 & 24.1 & $74 \cdot 4$ \\
\hline$\geq 126$ & 0.9 & 1.1 & $5 \cdot 9$ & 7.9 & 100 \\
\hline
\end{tabular}

FPG, fasting plasma glucose; 2hr PG, 2-hour postchallenge glucose; BMI, body mass index, DM, diabetes mellitus. 